\title{
Fátima da Silva Grave Ortiz* \\ Sobre o processo de formação da consciência: limites e potencialidades para a afirmação de projetos coletivos
}

About the process of conscience constitution:

limits and potentialities to the collective projects affirmation

\begin{abstract}
Resumo: O texto tem por objetivo contribuir com a análise do processo de constituição da consciência e da alienação, mostrando suas particularidades na ordem capitalista. Objetiva ainda fundamentar a necessidade de fortalecimento da consciência crítica para a construção de uma nova ordem societária. Parte do pressuposto que a consciência não é uma condição natural do homem, mas um processo que se constitui a partir da relação do homem com o trabalho. Esta relação se transforma durante a história, em especial com o capitalismo, que gera particulares formas de alienação. Este processo incide diretamente sobre a capacidade que os sujeitos têm de associarem-se a projetos coletivos

Palavras-chave: trabalho, consciência, alienação, projetos coletivos.
\end{abstract}

Abstract: The text intends to contribute to the analysis of constitution process of conscience and alienation, showing its particularities in the capitalist order. It intends to support the critical conscience to build a new social order. It assumes that conscience is not a natural condition of man, but a process that is based on the relationship of man with the work. This relationship changes during the history, especially with the capitalism, which creates different kinds of alienation. This process directly affects the ability of the subjects have to join in collective projects.

Keywords: work, conscience, alienation, collective projects.

* Assistente social, mestre e doutora em Serviço Social pela Universidade Federal do Rio de Janeiro (UFRJ) e professora adjunta da Escola de Serviço Social da Universidade Federal do Rio de Janeiro (ESS/UFRJ). E-mail: fgrave@oi.com.br. 
ReVistid QII paUtid

\} SOBRE O PROCESSO DE FORMAÇÃO DA CONSCIÊNCIA - ORTIZ, F. S. G. \}

\section{Introdução}

A tentativa de se analisar teoricamente a relação entre a consciência humana e a constituição e desenvolvimento dos processos históricos pauta-se na nossa observação cotidiana quanto à dificuldade vivenciada pelos sujeitos de um modo geral de se associarem aos princípios e posturas concernentes a projetos coletivos.

No caso do Serviço Social, pelo menos desde os anos 1990, nossas entidades e literatura mais crítica têm nos apontado a necessidade de a categoria profissional - através de seus sujeitos individuais e coletivos - aderir e defender os princípios presentes no conjunto de documentos que embasam o exercício e a formação profissional: o Código de Ética de 1993, as Diretrizes Curriculares da Associação Brasileira de Ensino e Pesquisa em Serviço Social (ABEPSS) e a Lei de Regulamentação. Juntos, esses documentos partilham de uma mesma concepção de homem e de mundo que atravessam o que chamamos de projeto ético-político profissional.

Trata-se de um projeto profissional vinculado a um projeto de sociedade que, como todos os projetos coletivos, não prescinde dos sujeitos. São os homens indivíduos sociais - que vivenciam em todas as suas expressões os dilemas e as potencialidades de um projeto coletivo. E, neste sentido, é necessário que esses homens conheçam e apreendam os princípios que os regem. No entanto, esta não é uma tarefa simples. Ao contrário, tais sujeitos não estão imunes aos efeitos alienadores do fetichismo e da reificação presentes na sociedade burguesa.

Deste modo, embora, dados os limites deste texto, não tenhamos tratado as particularidades assumidas pelo Serviço Social e seu projeto profissional em face da ordem burguesa, é inegável que a apreensão dos fundamentos envolvidos no processo de formação da consciência e da alienação nos apontam mediações necessárias para o entendimento sobre as possibilidades e dificuldades enfrentadas cotidianamente pelos sujeitos profissionais - individuais e coletivos - na defesa dos princípios e concepções subjacentes ao projeto ético-político, uma vez que eles se encontram na contracorrente da ordem social hegemônica.

Neste sentido, este texto, constituído a partir de ampla revisão da literatura afim, tem por objetivo contribuir com a análise do processo de constituição da consciência e da alienação, mostrando suas particularidades na ordem capitalista. Objetiva ainda fundamentar a necessidade de fortalecimento da consciência crítica para a construção de uma nova ordem societária sem exploração de qualquer natureza e sem a propriedade privada dos meios de produção.

\section{Trabalho e o processo de constituição da consciência}

Observando a trajetória da filosofia, identifica-se que uma preocupação que por um longo período esteve presente entre os pensadores foi a relação existente entre matéria e espírito ou entre ser e consciência. Assim, ainda que esta relação e sua abordagem tenham tomado conteúdos bastante diferenciados desde os antigos filósofos, podemos para efeito deste artigo sublinhar que, já nos idos da modernidade, a polêmica entre ser e consciência pautou-se entre basicamente duas tendências principais - o idealismo e o materialismo, e estes com suas diferenciações internas: no caso da perspectiva idealista, referimo-nos ao idealismo subjetivo de Kant e sua 


\section{ReVistg all paUt:}

\{ SOBRE O PROCESSO DE FORMAÇÃO DA CONSCIÊNCIA - ORTIZ, F. S. G.\}

vertente objetiva em Hegel; e para o materialismo, o chamado materialismo mecanicista (ou "vulgar") de Feuerbach e o materialismo histórico-dialético de Marx e Engels (LESSA; TONET, 2008; FREDERICO, 1995).

Longe de concluir este tema, em linhas gerais podemos afirmar que para os idealistas a existência do ser é determinada pela consciência. A célebre frase de Descartes - "penso, logo existo" - denota exatamente este entendimento, que os homens apenas podem ser identificados como homens porque pensam, porque são seres racionais. Esta é a condição que inclusive os diferencia dos animais, conferindoIhes superioridade sobre estes.

Bastante atual, a perspectiva idealista se renova nos dias de hoje a partir da defesa de algumas máximas baseadas na "força do pensamento", do "pensar positivo", da vontade como aquela que ultrapassa obstáculos, ou no peso consagrado da autoestima, como facilitador das diversas situações vividas pelos sujeitos. Com uma clara autonomia entre o pensar e o agir, é como se as ideias por si fossem capazes de transformar a realidade.

Em direção oposta, o materialismo afirma que é a existência do ser (com as demandas materiais que lhe são inerentes) que determina seu modo de pensar. Portanto, o ser determina a consciência. No entanto, contrastando com o materialismo feuerbachiano, no qual, em linhas gerais, tudo é matéria, inclusive as ideias, a perspectiva materialista presente nas obras de Marx e Engels não identifica ser e consciência, ainda que ambos integrem dialeticamente a mesma unidade - faces diferentes de um mesmo todo. Para esses pensadores, "[...] os homens, ao desenvolverem sua produção material e seu intercâmbio material, transformam também, com esta sua realidade, seu pensar e os produtos de seu pensar. Não é a consciência que determina a vida, mas a vida que determina a consciência" (MARX; ENGELS, 1993, p. 37).

Com efeito, a história será o produto da relação deste ser com a natureza que o cerca. ${ }^{1}$ Não possui uma perspectiva abstrata ou natural, mas é feita, no dizer de Marx e Engels, pelos homens de carne e osso que convivem na realidade. Neste sentido, a constituição das representações ideais que fazemos sobre a vida e seus processos e fenômenos não é um processo abstrato, ao contrário;

a produção de ideias, de representações, da consciência, está, de início, diretamente entrelaçada com a atividade material e com o intercâmbio material dos homens, como a linguagem da

\footnotetext{
1 Marx e Engels criticam claramente em A ideologia alemã a perspectiva hegeliana de história, para quem esta se constituía a partir da evolução das ideias dos homens. Cabe destacar que para Hegel nem todos os homens eram capazes de fazer a história, mas apenas alguns, considerados por ele como afortunados, pois encarnavam o Espírito Absoluto, os demais eram levados pela história. Ainda conforme Marx e Engels, a concepção hegeliana tornava a história um ente metafísico, tendo em vista que, conforme Hegel, "o homem existe para que a história possa existir e esta existe para que a demonstração das verdades possa existir" (1993, p. 59). Assim, "toda concepção histórica até o momento, ou tem omitido completamente esta base real da história, ou a tem considerado como algo secundário, sem qualquer conexão com o curso da história. Isto faz com que a história deva sempre ser escrita de acordo com um critério situado fora dela. A produção da vida real aparece como algo separado da vida comum, como algo extra e supraterrestre. Com isto, a relação dos homens com a natureza é excluída da história, o que engendra a oposição entre natureza e história. Consequentemente, tal concepção apenas vê na história as ações políticas dos príncipes e do Estado, as lutas religiosas e as lutas teóricas em geral, ê vê-se obrigado especialmente a compartilhar em cada época histórica, a ilusão dessa época" (1993, p. 57).
}

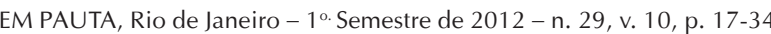




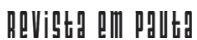

\} SOBRE O PROCESSO DE FORMAÇÃO DA CONSCIÊNCIA - ORTIZ, F. S. G.\}

vida real. O representar, o pensar, o intercâmbio espiritual dos homens, aparecem aqui como emanação direta de seu comportamento material (MARX; ENGELS, 1993, p. 36).

Desta forma, Marx e Engels atribuem à necessidade de intercâmbio entre os homens, e destes com a natureza, o surgimento da consciência (assim como da linguagem) na constituição da vida material. O processo de constituição da consciência é paulatino e histórico, pois,

[...] o animal não se 'relaciona' com nada, simplesmente não se relaciona. Para o animal, sua relação com os outros não existe como relação. A consciência, portanto, é desde o início um produto social, e continuará sendo enquanto existirem homens. A consciência é, naturalmente, antes de mais nada mera consciência do meio sensível mais próximo e a consciência da conexão limitada com outras pessoas e coisas situadas fora do indivíduo que se torna consciente [...] (MARX; ENGELS, 1993, p. 43).

Depreende-se do dizer de Marx e Engels (1993) que o processo de constituição da consciência humana desenvolve-se gradativamente à medida que os homens se relacionam entre si e aprimoram neste sentido as respostas às suas necessidades.

Em tempos primitivos, o homem possuía a consciência apenas do que lhe era bastante próximo e sensível e, nesta condição, pouco se distanciava de um animal. O processo de aperfeiçoamento e complexificação da consciência são proporcionais ao crescimento e desenvolvimento do homem como ser social e seus processos correlatos como o surgimento da propriedade e da divisão social do trabalho.

A partir deste momento, a consciência pode realmente imaginar ser algo diferente da consciência da práxis existente, representar realmente algo sem representar algo real; desde este instante, a consciência está em condições de emancipar-se do mundo e entregar-se à criação da teoria, da teologia, da filosofia, da moral e etc. (MARX; ENGELS, 1993, p. 45).

Em síntese, os homens não são seres conscientes porque pensam simplesmente, porque são racionais, mas se tornam conscientes porque trabalham como homens, idealizando previamente os resultados esperados para o atendimento de uma dada necessidade.

Diferentemente da atividade realizadas pelos demais seres (FREDERICO, 1995; LESSA, 2002), trabalho humano é o único no qual o resultado esperado já existia idealmente na cabeça do homem. A conhecida citação marxiana, neste sentido, é inconteste,

Uma aranha executa operações semelhantes às do tecelão, e a abelha supera mais de um arquiteto ao construir sua colmeia. 
Revista RM PaUth

\{ SOBRE O PROCESSO DE FORMAÇÃO DA CONSCIÊNCIA - ORTIZ, F. S. G.\}

Mas o que distingue o pior arquiteto da melhor abelha é que ele figura na mente sua construção antes de transformá-la em realidade. No fim do processo de trabalho se the aparece um resultado que já existia antes idealmente na imagem do trabalhador (MARX, 2001, p. 202).

Assim, a teleologia é a capacidade exclusivamente humana de projetar idealmente algo que se deseja construir para o atendimento à necessidade. O agir humano é sempre interessado, parte sempre de algum interesse, de alguma finalidade. Contudo, nem sempre o produto do trabalho humano possui a exata semelhança com aquilo que tinha sido outrora idealizado (passado pela prévia ideação). ${ }^{2}$ Essa oportuna idiossincrasia resulta do fato de que nosso desejo e idealizações se chocam com as causalidades existentes, ou seja, com as legalidades que "causam" o movimento e compõem determinado ser (ou objeto).

Destaca-se ainda que, por meio da teleologia, o homem é capaz, em seu processo de trabalho, de atribuir ao ser novas causalidades, também chamadas "causalidades postas" (LESSA, 2002). Ou seja, no processo de trabalho humano, a causalidade transforma-se por meio da teleologia em "causalidade posta", uma vez que,

[...] a objetividade primária do ser se subordina a dadas posições teleológicas, as quais têm o poder de articular as propriedades da natureza em novas formas e relações, dando origem a uma nova objetividade (o mundo dos homens); mas tendo também o limite de não poder alterar o caráter ontológico primário do ser. A causalidade posta, portanto, continua a ser causalidade, não se transmutando em teleologia - todavia, por ser causalidade posta, está articulada a uma nova malha causal cuja origem é necessariamente a atividade teleologicamente orientada (LESSA, 2002, p. 74).

O confronto dialético de teleologias e causalidades engendra uma nova objetividade social, chamada por Lukács de "segunda natureza". Na verdade, por meio do trabalho humano, os diversos objetos - que antes apenas existiam no plano das ideias e depois de confrontados com as causalidades existentes - objetivam-se, tornando-se independentes daquele que os criou. Estes processos chamados de "objetivação" e "exteriorização" respectivamente fazem com que os novos objetos

\footnotetext{
2 Partilhando do mesmo entendimento, Heller (1972, p. 1) afirma que "[...] os homens aspiram a certos fins, mas estes estão determinados pelas circunstâncias, as quais, de resto, modificam tais esforços e aspirações, produzindo desse modo resultados que divergem dos fins inicialmente colocados [...]" (p. 1) E de que circunstâncias, a autora se refere? Para ela, "[...] a 'circunstância' é a unidade de forças produtivas, estrutura social e formas de pensamento, ou seja, um complexo que contem inúmeras posições teleológicas, a resultante objetiva de tais posições teleológicas. [...] Causalidade e finalidade, portanto, são em Marx fatos ontológico-sociais que necessariamente se relacionam." (Idem, p. 2).
}

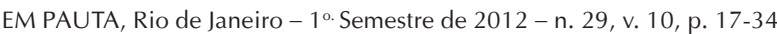


ReVista all paltid

\} SOBRE O PROCESSO DE FORMAÇÃO DA CONSCIÊNCIA - ORTIZ, F. S. G. \}

passem a ocupar um lugar inédito na história e no "mundo dos homens" (LESSA, 2002), e, por conseguinte, gerando uma "segunda natureza" capaz de abrigar um conjunto de novas causalidades.

A objetivação é, segundo Lukács, o momento do trabalho pelo qual a teleologia se transmuta em causalidade posta. [...] Ela articula a idealidade da teleologia com a materialidade do real sem que, por essa articulação, a teleologia e a causalidade percam suas respectivas essências, deixem de ser ontologicamente distintas (LESSA, 2002, p. 75).

Assim, o processo histórico de constituição do homem (este fundado a partir do trabalho, tal como afirmamos em linhas anteriores) revela o processo de formação de sua consciência. Este é atravessado simultânea e dialeticamente pelas dimensões da universalidade e da singularidade, gerando um modo particular de consciência, pois ao mesmo tempo em que nossa consciência revela o mundo objetivo que nos é apresentado (e esta apresentação expressa a história de uma época e as clivagens de classe, de gênero e de etnia), cada um dos sujeitos desenvolve um modo e um percurso singular para seu desenvolvimento enquanto ser consciente.

No dizer de lasi (2011) é claro o entendimento que o processo de tomada de consciência não se dá a todos do mesmo jeito ou na mesma velocidade, pois "esse processo é ao mesmo tempo múltiplo e uno. Cada indivíduo vive sua própria superação particular, transita de certas concepções de mundo até outras, vive subjetivamente a trama de relações que compõem a base material de sua concepção de mundo" (IASI, 2011, p. 13).

Trata-se, assim, de um processo no qual o homem torna-se consciente - não se tratando, assim, de um processo natural. Ao contrário, à medida que as bases materiais por meio do trabalho se complexificam, criando uma nova objetividade social, também se desenvolve a consciência humana. Tal desenvolvimento é, portanto histórico, mas também incorporado pelos homens por um processo bastante particular, que os torna indivíduos sociais (simultaneamente expressão de sua singularidade e do gênero humano).

Este processo de afirmação do homem como um ser consciente se inicia tão logo o mesmo se percebe enquanto sujeito em sua vida cotidiana ainda na infância. É no cotidiano que o homem capta as primeiras informações e visões sobre a realidade que o cerca. Não necessário dizer que com todas as limitações que o cotidiano impõe (HELLER, 1972), uma delas nos cabe destacar - a ultrageneralização, na qual o homem toma o todo pela parte. Deste modo, "a percepção generalizada da vivência particular não apenas se baliza em valores como deforma a realidade pela transposição de juízos presos à particularidade" (IASI, 2011, p. 24).

Ao longo de sua vida, o homem recebe outras informações, às vezes mais elaboradas, sob a forma de conhecimento, que sedimentam determinadas concepções de mundo (geralmente vinculadas ao pensamento dominante e hegemônico), que mais tarde serão incorporadas pelo sujeito como se fossem absolutamente suas e sobre as quais ele adere voluntariamente. A naturalização e mora- 


\section{ReVistg all paUt:}

\} SOBRE O PROCESSO DE FORMAÇÃO DA CONSCIÊNCIA - ORTIZ, F. S. G. \}

lização dos processos sociais ${ }^{3}$ residem exatamente neste processo de adesão "voluntária" dos sujeitos, que reproduzem posturas e ações sem conhecer seus fundamentos.

A leitura e análise crítica da realidade nos permite entender que na verdade,

aquilo que é visto pela pessoa em formação como mundo externo, como objetividade inquestionável, portanto, como realidade, é apenas uma forma particular, historicamente determinada, de se organizarem as relações familiares. No entanto, esse caráter particular não é captado pelo indivíduo, que passa a assumi-lo como natural (IASI, 2011, p. 17).

Com efeito, o processo de construção da consciência será irremediavelmente fundado a partir dos movimentos que tendem a naturalizar e moralizar nossa estrutura de pensamento, gerando posturas e concepções vinculadas ao acervo ideológico da classe dominante - isto nos remete a dificuldade que de antemão já se encontram aqueles que, como os assistentes sociais brasileiros, pretendem construir uma consciência renovada, vinculada a outra perspectiva societária e valorativa (como no caso de nosso projeto profissional), tendo em vista que,

as ideias da classe dominante são, em cada época, as ideias dominantes; isto é, a classe que é a força material dominante da sociedade é, ao mesmo tempo, sua força espiritual dominante. A classe que tem a sua disposição os meios de produção material dispõe, ao mesmo tempo, dos meios de produção espiritual, o que faz com que a ela sejam submetidas, ao mesmo tempo e em média, as ideias daqueles aos quais faltam os meios de produção espiritual. [...] Os indivíduos que constituem a classe dominante possuem, entre outras coisas, também consciência e, por isso pensam; na medida em que dominam como classe e determinam todo o âmbito de uma época histórica, é evidente que o façam em toda a sua extensão e, consequentemente, entre outras coisas, dominem também como pensadores, como produtores de ideias, que regulem a produção e a distribuição das ideias de seu tempo e que suas ideias sejam por isso mesmo, as ideias dominantes da época. (MARX; ENGELS, 1993, p. 72).

\footnotetext{
${ }^{3} \mathrm{Na}$ ordem burguesa, observamos simultaneamente a existência das tendências de naturalização e de moralização dos processos sociais, que se expressam tanto no nível da apreensão quanto da intervenção sobre os mesmos. No entanto, ainda que geralmente autoimplicadas, identificam-se particularidades entre ambas. Enquanto a naturalização explica à existência, por exemplo, as desigualdades como produto da natureza (sobre o que pouco se pode fazer), a moralização as justifica a partir da atribuição de juízos de valor. Ressalta-se que para ambas as tendências - naturalização e moralização - não se consideram as determinações sócio-históricas pertinentes aos processos sociais. Ao contrário, trata-se somente do indivíduo, que, a partir de suas qualidades inatas e valores morais, consiste no único responsável pelos processos que vivencia ou representa.
}

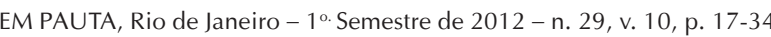




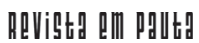

\} SOBRE O PROCESSO DE FORMAÇÃO DA CONSCIÊNCIA - ORTIZ, F. S. G.\}

Assim, não é simples se romper com o modo capitalista de pensar, visto que os conteúdos valorativos dominantes apreendidos durante a vida do sujeito consciente são incorporados por este sem questionamento, de forma alienada. A alienação - fenômeno que no capitalismo se amplia - atua no sentido de ratificar tais conteúdos, embaçando a consciência verdadeiramente humana.

\section{Consciência e alienação: impasses a formação de uma consciência crítica}

Os homens fazem sua própria história, mas não a fazem como querem; não a fazem sob circunstâncias de sua escolha e sim sob aquelas com que se defrontam diretamente, legadas e transmitidas pelo passado. A tradição de todas as gerações mortas oprime como um pesadelo o cérebro dos vivos. (MARX, 1974, p. 335).

A frase de Marx presente em sua obra O 18 Brumário de Luis Bonaparte, além de nos deixar claro que a análise e transformação da realidade deve considerar que o pôr teleológico do homem confronta-se sempre com as causalidades presentes na sociedade, também deve nos iluminar quanto ao entendimento acerca do processo de constituição da consciência.

O legado material e espiritual construído social e historicamente incide diretamente sobre as condições sobre as quais se forma nossa consciência. Assim, considerando que, conforme já dito antes, "as ideias da classe dominante serão as ideias dominantes daquela época" (MARX, 1993), a forma de pensar será completamente atravessada pelo modo de pensar hegemônico.

Conforme lasi (2011, p. 20), a alienação será, portanto, a primeira forma de consciência humana e, a partir disso, estão postas as bases para o florescimento da ideologia.

Assim, "a alienação que se expressa na primeira forma da consciência é subjetiva, profundamente enraizada como carga afetiva, baseada em modelos e identificações de fundo psicológico" (IASI, 2011, p. 20). Sendo o sujeito medularmente alienado, a ideologia - expressa a partir dos interesses e perspectivas daqueles que detém a dominação - introduzirá socialmente determinadas concepções de homem e de mundo (que são genuinamente particulares, pois afeitas a uma classe específica) como universais, gerando uma "falsa consciência". "Falsa" não no sentido de que não existe, mas porque embaça o real.

No entanto, cabe-nos destacar que a alienação não emerge exclusivamente sob a égide do capitalismo (embora, neste modo de produção, esta assuma particularidades importantíssimas). Trata-se de um processo muito anterior à ordem burguesa, cujos fundamentos repousam no surgimento da propriedade privada dos meios de produção e da divisão social do trabalho.

Em linhas gerais, podemos afirmar que é no processo de constituição histórica do homem que repousam as determinações histórico-sociais da gênese da alienação. Na primeira parte deste texto, apresentamos a centralidade do trabalho na formação do homem como portador do ser social, pois é somente por meio do trabalho que o 


\section{ReVistg all paUt:}

\{ SOBRE O PROCESSO DE FORMAÇÃO DA CONSCIÊNCIA - ORTIZ, F. S. G.\}

ser - antes primitivo - tornou-se homem. Mostramos também como, para responder às suas necessidades, o homem aciona sua capacidade de agir teleologicamente em face às causalidades, objetivando de fato aquilo que antes somente havia em seu pensamento, que passa a ocupar um lugar específico na história e no "mundo dos homens." (LESSA, 2002).

Esta nova objetividade social não se fez historicamente sem um rico e incessante desenvolvimento das forças produtivas, que, aprimorando o processo de produção, gerou cada vez mais a capacidade humana de produzir o excedente. Com a produção do excedente, um novo fenômeno emergiu na humanidade - a apropriação privada deste excedente por meio da violência, e com esta o nascimento da propriedade privada e da divisão da sociedade em classes sociais distintas e antagônicas. Estavam postas as condições objetivas e subjetivas para a divisão social do trabalho e, por conseguinte, para a fratura entre o pensar e o agir.

Conforme Konder,

Pode-se dizer, portanto, que foi a divisão do trabalho - com a escravização de alguns homens pelos outros - que proporcionou, nas condições de sumo atraso em que se realizou, uma intensificação no ritmo do progresso da humanidade, exercendo efeito estimulante sobre o desenvolvimento econômico das sociedades primitivas. Mas a divisão social do trabalho, o aparecimento da propriedade e a formação das classes sociais (três aspectos de um mesmo processo) não tiveram apenas um efeito positivo, impulsionando o desenvolvimento econômico e promovendo através da evidente desumanidade - um surto de progresso na evolução do homem. Coube-Ihes outra consequência, além de terrivelmente trágica, historicamente negativa: a dilaceração do homem, o fracionamento da humanidade, a ruptura da comunidade espontânea, a destruição da unidade humana primitiva. (2010, p. 62).

Assim, à medida que a produção do excedente gerou as condições materiais necessárias para o surgimento da propriedade privada e da divisão da sociedade em classes sociais e, por sua vez, da divisão social do trabalho, podemos afirmar que esses processos autoimplicados constituíram as bases para a formação de uma sociedade egoísta, na qual a disputa dos interesses singulares sobrepunha-se à cooperação anteriormente colocada na relação entre os homens.

Com relação a isso, Konder (2010) atenta para o fato de que, com o fim do padrão de vida baseado na cooperação entre os membros da coletividade, no qual todos possuíam "[...] um ponto de vista naturalmente comum a todos os homens no exame de todos os problemas relativos à atividade humana [...]" (p. 68), finda o que o autor chama de "unidade espontânea primitiva". E nestes termos, ou seja, "com a destruição da unidade espontânea primitiva, cavou-se um fosso entre o indivíduo e a espécie humana" (Idem, p.68). Depreende-se daí, portanto, que vêm de muito longe as raízes do individualismo e da dificuldade dos homens em se conceberem 


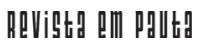

\} SOBRE O PROCESSO DE FORMAÇÃO DA CONSCIÊNCIA - ORTIZ, F. S. G. \}

como "indivíduos sociais" - partícipes do gênero humano - e passíveis de associação a projetos coletivos.

No dizer de Konder, estão colocados os fundamentos sociais e históricos da alienação, tendo em vista que,

Por força da cisão entre o indivíduo e a espécie, os indivíduos tendem a ter deles mesmos uma visão mutilada, uma vez que não se veem como indivíduos integrados normalmente numa espécie. Torna-se difícil compreender claramente a unidade do gênero humano, pois esta unidade se acha duramente atingida, na prática, pela divisão do trabalho e pela propriedade privada. Passam a faltar-lhes condições que propiciem uma clara percepção daquilo que eles possuem de comum uns com os outros; e as diferenciações individuais passam a ser observadas independentemente da história concreta e das condições materiais de vida dos homens. (2010, p. 70).

Assim, o trabalho - categoria central no processo de autocriação do homem - assume com a divisão social do trabalho a "raiz causal de todo o complexo de alienações", tal como afirma Mészáros (2006, p.20), expandindo-se para os terrenos da moral, da política, da religião, da arte e da ciência.

No capitalismo, porém, a alienação particulariza-se. A ordem burguesa não apenas reproduz os processos milenares pautados na divisão da sociedade em classes, na propriedade privada e na divisão social do trabalho, mas, sobretudo, os aprofunda, tendo em vista que, pela primeira vez na história da humanidade, funda-se uma sociedade, cuja finalidade é a produção capitalista de mercadorias, gerando a "mercadorização" da vida e a coisificação dos homens. Conforme Konder, a mercadoria impõe-se ao trabalhador, pois toda a vida passa a se organizar para sua produção: "[...] o mundo do produto - da mercadoria - passa a impor suas exigências e os seus valores ao mundo dos produtores" (2010, p. 42).

O fetichismo da mercadoria, bem como a reificação, particularizam o fenômeno da alienação na ordem burguesa. No dizer de Netto,

o fetichismo implica a alienação, realiza uma alienação determinada e não opera compulsoriamente a evicção das formas alienadas mais arcaicas. O que ele instaura, entretanto, é uma forma nova e inédita que a alienação adquire na sociedade burguesa constituída, assim entendidas as formações econômicosociais embasadas no modo de produção capitalista dominante, consolidado e desenvolvido. (1981, p. 74).

No caso do fetichismo, ele se põe a partir das relações mercantis. Estas promovem o fetichismo a partir de alguns aspectos, dentre eles o fato de que na produção de uma dada mercadoria comparecem muitas outras (incluindo matérias-primas) e processos de trabalho, que são encobertos durante a criação da mesma. 
Revista RM PaUth

\{ SOBRE O PROCESSO DE FORMAÇÃO DA CONSCIÊNCIA - ORTIZ, F. S. G. \}

A mercadoria é misteriosa simplesmente por encobrir as características sociais do próprio trabalho dos homens, apresentandoas como características materiais e propriedades sociais inerentes aos produtos do trabalho; por ocultar, portanto, a relação social entre os trabalhos individuais dos produtores e o trabalho total, ao refleti-la como relação social existente, à margem deles, entre os produtos do seu próprio trabalho. [...] Uma relação social definida, estabelecida entre os homens, assume a forma fantasmagórica de uma relação entre coisas. (MARX, 2001, p. 94).

Além disso, o produtor precisa trocar sua mercadoria no mercado por um equivalente, ou seja, por uma mercadoria, cujo valor, que é determinado pelo tempo de trabalho socialmente necessário para a sua produção, seja equivalente. Assim, é a lei do valor que determina o grau de equivalência entre as mercadorias. Conforme Marx (2001, p. 77), "[...] a mercadoria assume a forma de equivalente, por ser diretamente permutável por outra". O surgimento do dinheiro como equivalente universal na troca de mercadorias irá aprofundar ainda mais essas relações, e com isso, o fetichismo.

Este processo como um todo autonomiza a mercadoria em face ao seu criador, portanto, no mercado a relação entre as mercadorias assume o centro e não a relação entre os produtores. No processo de produção capitalista, o trabalhador não produz mercadorias apenas em função do seu valor de uso, mas principalmente pelo seu valor de troca. Ainda que o valor de uso das mercadorias não seja extinto, ${ }^{4}$ a produção capitalista de mercadorias produz objetos eminentemente para serem trocados, pois,

Se prescindirmos do valor-de-uso da mercadoria, só lhe resta ainda uma propriedade, a de ser produto do trabalho. Mas, então, o produto do trabalho já terá passado por uma transmutação. Pondo de lado seu valor-de-uso, abstraímos, também, das formas e elementos materiais que fazem dele um valor-de-uso. Ele não é mais mesa, casa, fio ou qualquer outra coisa útil. Sumiram todas as suas qualidades materiais. Também não é mais o produto do trabalho do marceneiro, do pedreiro, do fiandeiro ou de qualquer outra forma de trabalho produtivo. Ao desaparecer o caráter útil dos produtos do trabalho, também desaparece o caráter útil dos trabalhos neles corporificados; desvanecem-se, portanto, as diferentes formas de trabalho concreto, elas não mais se distinguem umas das outras, mas reduzem-se, todas, a uma única espécie de trabalho, o trabalho humano abstrato. (MARX, 2001, p. 60). ${ }^{4}$ Quanto à utilidade das mercadorias em meio ao seu valor de troca, é preciso recuperar Marx (2001, p.57): "A
mercadoria é, antes de mais nada, um objeto externo, uma coisa que, por suas propriedades, satisfaz necessidades
humanas, seja qual for a natureza, a origem delas, provenham do estômago ou da fantasia. Não importa a
maneira como a coisa satisfaz a necessidade humana, se diretamente, como meio de subsistência, objeto de consumo, ou indiretamente, como meio de produção".

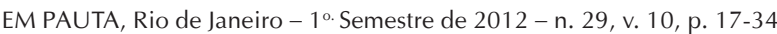




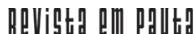

\} SOBRE O PROCESSO DE FORMAÇÃO DA CONSCIÊNCIA - ORTIZ, F. S. G. \}

Assim, mais que produzir mercadorias com determinada utilidade, o trabalho na ordem burguesa produz mercadorias para serem trocadas, e neste sentido para o trabalhador tanto faz que o produto do seu trabalho seja sapatos ou casacos, pois mais que valores de uso, o homem produz valores de troca, daí o caráter abstrato do trabalho humano na ordem capitalista.

Essa relação estranhada do homem com seu trabalho gera na ordem burguesa uma profunda alienação, tendo em vista que, no dizer do próprio Marx,

[...] o trabalho alienado 1) aliena a natureza do homem, 2) aliena o homem de si mesmo, a sua função ativa, a sua atividade vital, aliena igualmente o homem a respeito da espécie; transforma a vida genérica em meio da vida individual. Em primeiro lugar, aliena a vida genérica e a vida individual; em seguida, muda esta última na sua abstração em objetivo da primeira, na sua forma abstrata e alienada. (1993, p. 164).

E, além disso,

[...] o trabalho alienado transforma: 3) a vida genérica do homem, e também a natureza enquanto sua propriedade genérica espiritual, em ser estranho, em meio da sua existência individual. Aliena do homem o próprio corpo, bem como a natureza externa, a sua vida intelectual, a sua vida humana. 4) Uma consequência imediata da alienação do homem a respeito do produto de seu trabalho, da sua vida genérica, é a alienação do homem relativamente ao homem. Quando o homem se contrapõe a si mesmo, entra igualmente em oposição com os outros homens. (MARX, 1993, p. 166).

Com efeito, ainda que a alienação seja um fenômeno, cujas determinações sociais situam-se historicamente anteriores ao capitalismo, é neste estágio civilizatório que suas modalidades - fetichismo e reificação - se particularizam. ${ }^{5}$

Desta forma, observa-se que o desenvolvimento da sociedade capitalista não foi capaz (justamente por estar assentada na propriedade privada dos meios de produção e na exploração do trabalho humano para a manutenção desta) de superar a alienação humana. Ao contrário, tornou a alienação um fenômeno universal (NETTO, 1981), estendendo-a a todos os campos da vida social, incluindo as relações privadas e pessoais.

A reificação traz para os espaços privados, domésticos, e até afetivos, a mesma lógica alienada da produção capitalista de mercadorias, típica das relações mercantis, que exige que as mesmas sejam úteis para serem trocadas. Como consequência,

5"O que especifica historicamente a sociedade burguesa constituída é que ela, sem cortar com as formas alienadas que vem das sociedades que a precederam [...], instaura processos alienantes particulares, aqueles postos pelo fetichismo e que redundam em formas alienadas específicas, as reificadas." (NETTO, 1981, p. 75). 


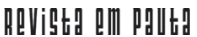

\{ SOBRE O PROCESSO DE FORMAÇÃO DA CONSCIÊNCIA - ORTIZ, F. S. G.\}

observa-se que as relações humanas passam a basear-se a partir do utilitarismo moral, no qual "[...] as relações humanas são valorizadas segundo sua utilidade: é bom o que for útil; é útil o que satisfizer necessidades materiais" (BARROCO, 2008, p. 158).

Este fenômeno - também identificado por "coisificação" - transfere aos homens a qualidade da mercadoria, para a qual o equivalente universal "dinheiro", tudo pode comprar. Marx, nos Manuscritos Econômico-Filosóficos de 1844, já atentava para processos, que, após mais de um século, são infelizmente bastante comuns entre nós e que dizem respeito ao papel do dinheiro na sociedade burguesa, cabendo aqui destacar um trecho daquela obra:

Sou feio, mas posso comprar a mais bela mulher para mim. Consequentemente, não sou feio, pois o efeito da feiura, seu poder de repulsa, é anulado pelo dinheiro. Como indivíduo, sou coxo, mas o dinheiro proporciona-me vinte e quatro pernas; logo, não sou coxo. Sou um homem detestável, sem princípios, sem escrúpulos e estúpido, mas o dinheiro é acatado e assim também o seu possuidor. O dinheiro é o bem supremo, e por isso seu possuidor é bom. [...] O que sou incapaz de fazer como homem, e, pois, o que todas as minhas faculdades individuais são incapazes de fazer, me é possibilitado pelo dinheiro. O dinheiro, por conseguinte, transforma cada uma dessas faculdades em algo que ela não é em seu antônimo. [...] Aquele que pode comprar a bravura é bravo, malgrado seja covarde. O dinheiro não é trocado por uma qualidade particular, uma coisa particular ou uma faculdade humana específica, porém por todo o mundo objetivo do homem e da natureza. Assim, sob o ponto de vista de seu possuidor, ele troca toda qualidade e objeto por qualquer outro, ainda que sejam contraditórios. Ele é a confraternização dos incomparáveis; força os contrários a abraçarem-se. (MARX, 1993, p. 232).

O dinheiro que a tudo equivale tende a comprar nesta sociedade todas as coisas e as pessoas. A finalidade da vida não é desta feita, a emancipação e a partir desta o alcance da felicidade, pois apenas sujeitos emancipados plenamente têm condições materiais e espirituais de serem felizes. Ao contrário, por ter se tornado "coisa", o homem do capitalismo é aquele cuja finalidade da vida é ter dinheiro progressivamente. Apenas o dinheiro lhe confere poder e reconhecimento perante aos outros homens, daí a sua necessidade quase que orgânica.

Àqueles que conseguem captar criticamente esta armadilha e se colocam contra ela, cabe denunciar o fetichismo e a reificação presente nos processos sociais e assim contribuir na tentativa de construção de uma nova consciência. 


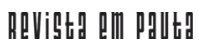

\} SOBRE O PROCESSO DE FORMAÇÃO DA CONSCIÊNCIA - ORTIZ, F. S. G. \}

\section{Da consciência em si à consciência revolucionária: uma transição} necessária para uma nova ordem social

O fetichismo - que incide diretamente sobre a destituição do caráter autocriador do trabalho humano - e a reificação - expressa basicamente na trasladação da lógica das relações mercantis para a vida como um todo, cujo ápice pode ser observado no papel assumido pelo dinheiro - podem ser entendidos como modalidades assumidas pela alienação na ordem burguesa. Consistem, sem dúvida, em processos, cuja complexidade incide na constituição da consciência dos homens, dificultando muito a superação das formas alienadas de pensar e agir.

Contudo, ainda que a alienação cristalize determinadas concepções de homem e de mundo mediante a naturalização (e também pela moralização) dos processos sociais que explicam, por exemplo, as causas da pobreza e das desigualdades, há conjunturas, especialmente aquelas evidenciadas pela crise econômica, em que tais "explicações" se tornam inócuas ou menos inquestionáveis. Ou seja, até os setores mais conservadores da burguesia não conseguem mais esconder as causas e consequências de determinados processos, provocando uma anacronia ideológica. "Alguém, por exemplo, que acreditasse que trabalhando conseguiria tudo o que se quer, mas passa a viver uma situação na qual, apesar de trabalhar muito, não consegue o mínimo para viver, vivencia uma contradição que pode levá-lo à revolta" (IASI, 2011, p. 28)

É possível, portanto, escapar da inércia que alienação imprime à nossa consciência, ainda que pela via da revolta e da indignação. Mas isso ainda não é suficiente, pois a revolta em si não é capaz de desvelar as contradições que atravessam os processos sociais, fortalecendo, via de regra, as saídas individuais e pontuais para o enfrentamento desse conjunto de questões.

A chamada "consciência em si" desenvolve-se quando aquelas saídas individuais prescritas para o enfrentamento desta crise ideológica são superadas por uma abordagem coletiva, geralmente presente nos movimentos sociais, dentre os quais o sindical (IASI, 2011). É um grau de consciência que se põe quando os trabalhadores percebem que as situações vivenciadas por eles na vida e no trabalho decorrem de sua condição de classe. Conseguem identificar que seus interesses são antagônicos àqueles que os empregam, superando assim a "ilusão jurídica" da igualdade. Este passo no processo de constituição da "consciência em si" é de fundamental importância, mas ainda é limitado, pois continua nos limites da própria ordem burguesa.

No dizer de lasi,

[...] apesar de 'consciente' de parte da contradição do sistema [...], a pessoa ainda trabalha, age, pensa sob a influência dos valores anteriormente assumidos, que, apesar de serem parte da mesma contradição, continuam sendo vistos pela pessoa como naturais e verdadeiros. (2011, p. 30).

Mészáros (2008) também identifica limites na "consciência em si" (conforme lasi, 2011), a qual ele chama de consciência de classe "contingente" ou "psicológica". 


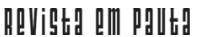

\{ SOBRE O PROCESSO DE FORMAÇÃO DA CONSCIÊNCIA - ORTIZ, F. S. G.\}

Para o autor, este grau de consciência não transcende a ordem burguesa porque, mesmo que os trabalhadores consigam conquistar melhorias ou reformas e pequenos avanços no sentido de reduzir as perdas produzidas a partir da condição de exploração e assalariamento, elas não superam as contradições da ordem burguesa. Para tanto, é preciso que essa consciência avance ainda mais, transitando a seu grau revolucionário.

[...] em sua luta revolucionária, não basta o proletariado assumirse enquanto classe (consciência em si), mas é necessário se assumir para além de si mesmo (consciência para si). Conceberse não apenas como um grupo particular com interesses próprios dentro da ordem capitalista, mas também se colocar diante da tarefa histórica da superação dessa ordem. A verdadeira consciência de classe é fruto dessa dupla negação: num primeiro momento, o proletariado nega o capitalismo assumindo sua posição de classe, para depois negar-se a si próprio enquanto classe, assumindo a luta de toda a sociedade por sua emancipação contra o capital. (IASI, 2011, p. 32).

O trânsito da consciência em si (ou "contingente" e "psicológica", no dizer de Mészáros, 2008) para a consciência revolucionária (ou "necessária" para o mesmo autor) é fundamental para a construção de uma nova ordem societária, tendo em vista que neste nível a classe trabalhadora se identifica e reconhece como detentora de uma missão histórica que supera o capitalismo. Esta autoidentificação dos trabaIhadores como a única classe capaz de portar esta missão revolucionária ${ }^{6}$ é imprescindível para a superação da ordem hegemônica, o que exige a organização política da classe e sua preparação para o processo de autoextinção.

Há aqui um dado importantíssimo que não podemos sublimar no processo de afirmação ou de superação de uma ordem social, que é o papel ativo que a consciência assume no movimento da realidade. No início deste texto, afirmávamos - sublinhando a perspectiva materialista histórico-dialética - que é a existência que determina a consciência e não o contrário, como afirmavam, e ainda afirmam, os idealistas. No entanto, sem desconsiderar a prioridade ontológica que a existência possui em face da consciência, é inconteste que este não é um processo de mão única, pois uma vez constituídas as ideias poderão ratificar ou questionar a hegemonia presente, incidindo sobre a existência.

Conforme Mészáros (2008, p. 57), a consciência “[...] tem uma estrutura própria relativamente autônoma, determinando assim, de forma recíproca, as estruturas econômicas da sociedade, ao mesmo tempo em que são também determinadas pela última."

\footnotetext{
${ }^{6}$ Cabe destacar que a burguesia consiste também numa "classe em si", mas jamais poderá transitar para a condição de "classe para si", pois defende necessidades e interesses particulares. Já a classe trabalhadora é a única que pode se colocar como "classe para si" porque "[...] é objetivamente capaz de estabelecer uma alternativa histórica viável à sua própria subordinação estrutural, bem como à necessidade de subordinar qualquer classe a qualquer outra" (MÉSZÁROS, 2008, p. 78).
}

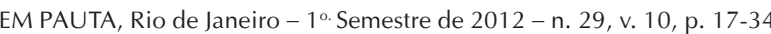

Revista da Faculdade de Serviço Social da Universidade do Estado do Rio de Janeiro 


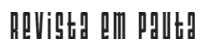

\} SOBRE O PROCESSO DE FORMAÇÃO DA CONSCIÊNCIA - ORTIZ, F. S. G.\}

Com efeito, se por um lado entendemos que "[...] o primeiro pressuposto de toda a existência humana, e, portanto, de toda a história, é que os homens devem estar em condições de viver para poder 'fazer história'" (MARX; ENGELS, 1993, p. 39), e, neste sentido, as condições objetivas incidem diretamente no processo de afirmação ou superação de uma consciência alienada; por outro, a luta pela construção de uma consciência crítica - e, por conseguinte, potencialmente revolucionária, é absolutamente necessária para o desenvolvimento das condições materiais de existência exigidas para o fortalecimento e ascensão de um novo projeto de sociedade. De acordo com Mészáros,

na visão de Marx, não é suficiente dizer que não pode haver 'autoextinção' sem a maturação de suas condições objetivas. Tem de se acrescentar também que as próprias condições objetivas não podem atingir sua maturidade total sem o desenvolvimento da autoconsciência como consciência da necessidade de desalienação. Assim, o fator 'subjetivo' adquire uma importância crucial como precondição necessária de sucesso nesse estágio altamente avançado do desenvolvimento humano, quando a questão em pauta é a extinção - a autoextinção - das condições de desumanização. (2008, p. 63).

Deste modo, se o processo de constituição histórica do homem a partir da centralidade do trabalho foi responsável pela configuração da consciência humana, deve-se entender que esta consciência, já amadurecida e complexificada pelos mesmos processos sócio-históricos, possui um papel fundamental na construção de uma nova sociedade. É preciso criar-se uma consciência progressivamente livre de alienação para a afirmação de uma nova ordem societária.

Para tanto, recuperamos aqui um pequeno trecho de Heller (1972) que, defendendo o papel que a ética ocupa no marxismo e na construção de outra sociedade, afirma:

Marx disse que, transformando o mundo, os homens se transformam a si mesmos. Não modificaremos substancialmente seu pensamento se alterarmos a sua frase e afirmarmos agora que não podemos transformar o mundo se, ao mesmo tempo, não nos transformarmos nós mesmos. (HELLER, 1972, p. 117).

\section{Considerações finais}

Durante nossa digressão procurou-se mostrar como a consciência não se constitui naturalmente, mas consiste em um processo no qual o homem torna-se consciente. Destaca-se também que este processo não se dá igualmente a todos os sujeitos; ao contrário, obedece a singularidade do ser consciente.

No entanto, um traço que acompanha a todos os sujeitos reside no fato de que os conteúdos valorativos que estes apreendem ao longo da vida pelos diversos 


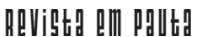

\{ SOBRE O PROCESSO DE FORMAÇÃO DA CONSCIÊNCIA - ORTIZ, F. S. G. \}

processos de socialização estão fundamentados no modo de ser e pensar dominante de uma dada época histórica. Daí a dificuldade do sujeito em reconhecer que o modo como ele pensa expressa uma parte do todo. O sujeito consciente acredita que as ideias que povoam seus pensamentos e ações são genuinamente suas, sem relação com a história e, portanto, sem relação com o gênero humano.

Imerso na alienação, o sujeito consciente tende a ratificar as posturas típicas de sua época, marcada por aqueles que detêm a propriedade privada dos meios de produção. No caso do capitalismo, afirmamos o individualismo, a posse, o não reconhecimento do outro como semelhante. Tais posturas inviabilizam a associação do ser consciente aos projetos coletivos, dificultam sua participação, negam sua existência, embaçam a condição do sujeito como indivíduo social, portador do ser social.

Os assistentes sociais não estão isentos disso, a despeito de uma possível adesão ao projeto profissional hegemônico, cujos princípios ético-políticos e perspectiva societária são antagônicos àqueles presentes na ordem burguesa. Identificar ações e iniciativas voltadas para o fortalecimento de uma consciência crítica é fundamental para os assistentes sociais em particular, e para os trabalhadores em linhas gerais. Assim, àqueles, como muitos assistentes sociais, que entendem e defendem a necessidade da construção de um projeto societário alternativo ao hegemônico, ou seja, que partilham do entendimento que é urgente a superação da ordem burguesa e a constituição de uma sociedade socialista e comunista, é absolutamente fundamental a denúncia do fetichismo e da reificação nos processos sociais e como singularmente os reproduzimos em nossa vida cotidiana, afirmando assim a ideologia dominante.

A luta contra tais processos - fetichismo e reificação - na sociedade burguesa e a ruptura com os mesmos faz parte da práxis revolucionária, uma vez que, para de fato superarmos a "pré-história da humanidade", precisamos mais que "[...] uma única ação revolucionária drástica e sim de uma revolução permanente [...]." (HELLER, 1972, p. 116), capaz de envolver "mentes e corações" na construção de uma nova consciência plenamente emancipada, o que passa, a nosso ver, por diversas esferas da vida social - a economia, a política, a ciência, a filosofia e precisamente, a ética. 


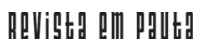

\} SOBRE O PROCESSO DE FORMAÇÃO DA CONSCIÊNCIA - ORTIZ, F. S. G.\}

\section{Referências}

BARROCO, M. L. S. Ética: fundamentos sócio-históricos. Biblioteca Básica/Serviço Social, São Paulo: Cortez Editora, 2008.

FREDERICO, C. O jovem Marx (1843-1844): as origens da ontologia do ser social, São Paulo: Cortez Editora, 1995.

HELLER, A. O cotidiano e a história. Rio de Janeiro: Paz e Terra, 1972.

IASI, M. L. Ensaios sobre consciência e emancipação. São Paulo: Expressão Popular, 2a. ed., 2011.

KONDER, L. Marxismo e alienação. São Paulo: Expressão Popular, 2010.

LESSA, S. Mundo dos homens: trabalho e ser social, São Paulo: Boitempo Editorial, 2002.

; TONET, I. Introdução à filosofia de Marx. São Paulo: Expressão Popular, 2008.

MARX, K. Manuscritos Econômicos-Filosóficos. Lisboa: Edições 70, 1993.

; ENGELS, F. A Ideologia Alemã. 9a. ed. São Paulo: HUCITEC, 1993.

. O 18 Brumário de Luis Bonaparte. Coleção Os Pensadores, volume XXXV, Rio de Janeiro: Abril Cultural, 1974.

O Capital: crítica da economia política, livro I, v. I, 18a. ed. Rio de Janeiro: Civilização Brasileira, 2001.

MÉSZÁROS, I. A teoria da alienação em Marx. São Paulo: Boitempo editorial, 2006. Filosofia, ideologia e ciência social. São Paulo: Boitempo, 2008.

NETTO, J. P. Capitalismo e reificação. São Paulo: Livraria Editora Ciências Humanas, 1981.

Recebido em 24de julho de 2012.

Aprovado para publicação em 16 de agosto de 2012. 